Article

\title{
Experimental Study on the Reinforcement of Prestressed Concrete Cylinder Pipes with External Prestressed Steel Strands
}

\author{
Lijun Zhao ${ }^{1,2}$, Tiesheng Dou ${ }^{1,2, *}$, Bingqing Cheng ${ }^{1,2}$, Shifa Xia ${ }^{1,2}$, Jinxin Yang ${ }^{3}$, Qi Zhang ${ }^{3}$, \\ Meng $\mathrm{Li}^{1,2}$ and Xiulin $\mathrm{Li}^{1}{ }^{1}$ \\ 1 Division of Materials, China Institute of Water Resources and Hydropower Research (IWHR), Beijing 100038, \\ China; jun15297669998@gmail.com (L.Z.); 18810179671@163.com (B.C.); xiasf@iwhr.com (S.X.); \\ limeng@iwhr.com (M.L.); lixl@iwhr.com (X.L.) \\ 2 State Key Laboratory of Simulation and Regulation of Water Cycle in River Basin, \\ China Institute of Water Resources and Hydropower Research (IWHR), Beijing 100038, China \\ 3 Beijing Institute of Water, Beijing 100044, China; yangjinxin@biwmail.com (J.Y.); \\ zhangqi@biwmail.com (Q.Z.) \\ * Correspondence: doutsh@iwhr.com; Tel.: +86-135-0120-7217
}

Received: 29 November 2018; Accepted: 26 December 2018; Published: 3 January 2019

\begin{abstract}
The prestressed concrete cylinder pipe (PCCP) suffers from cracks and degrades due to the prestress loss which is induced by wire breakage. Reinforcement with external prestressed strands is an option to return the deteriorating pipe's ability to withstand internal pressures. This reinforcement contributes to actively compensating for the prestress loss caused by broken wires at an economic price. The crack propagation in the core is constrained by the strands. Moreover, the high tensile strength of strands does not decrease with an increase in the bending angle. It is also unnecessary to dewater the pipes during construction. To evaluate the reinforcement effect, a prototype test of a PCCP was performed in an assembled apparatus. The apparatus was mainly constituted by two PCCPs whose internal diameter is $2000 \mathrm{~mm}$. The status of each component of the pipe was measured by resistance strain gauges in three sections along the axial direction at inverted $\left(360^{\circ}\right)$, crown $\left(180^{\circ}\right)$, and spring-line $\left(90^{\circ}, 270^{\circ}\right)$ orientations. The maximum width of the cracks in the outer concrete core at spring-line reduced from 1.2 to $0.1 \mathrm{~mm}$ after strengthening. The cracks of the core concrete changed slightly when the internal water pressure increased to the design pressure of $0.9 \mathrm{MPa}$. The strengthened pipe was capable of sustaining the design internal water pressure and the water tightness property was in a good state. The strains of the steel strands were all below the tensile strain level. The reinforcement of the PCCP with external prestressed steel strands is able to meet the strengthen requirement of the test.
\end{abstract}

Keywords: prestressed concrete cylinder pipe; external prestressed steel strands; wires breakage; strengthening effect

\section{Introduction}

A prestressed concrete cylinder pipe (PCCP) is a composite structure composed of a concrete core, a steel cylinder, prestressing wires and a mortar coating. A 3D diagram of the embedded prestressed concrete cylinder pipe (PCCPE) with bell and spigot joint rings is shown in Figure 1. It has several merits, such as a high capacity for withstanding loading, strong impermeability, strong durability, and cost-effectiveness [1]. PCCPs have been adopted for more than 70 years [2] since their invention in 1942, and have been widely utilized in long-distance pressured water transportation systems and municipal draining projects in the United States, Mexico, Canada, China and other countries. The amount of 
PCCPs installed in China has accumulated to $18,000 \mathrm{~km}$ within the past two decades [3,4] (by the end of 2015). A PCCP suffers from cracks and delamination of the mortar coating, corrosion and fractures of prestressing wires, longitudinal cracks in the concrete core and leakage of cylinders due to various factors such as overload, external corrosive environment, hydrogen embrittlement and water pressure fluctuation. PCCP failures may lead to a catastrophic loss without warning due to the pipes' dimension and high internal water pressure [5].

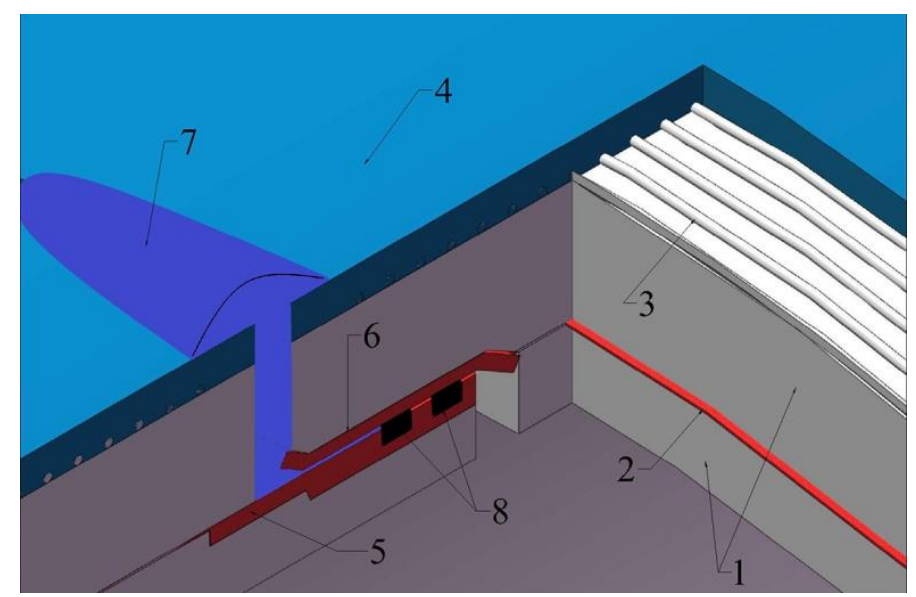

Figure 1. A 3D diagram of an embedded prestressed concrete cylinder pipe PCCPE: 1 -Concrete core; 2-Cylinder; 3-Prestressing wires; 4-Mortar coating; 5-Spigot ring; 6-Bell ring; 7-Grout; 8 - Rubber gasket.

To return the deteriorating pipe's ability to withstand the internal pressures, a series of studies involving the replacement, internal reinforcement (steel cylinder relining, steel cylinder slip-lining, carbon fiber reinforced polymer (CFRP) reinforcement), external reinforcement (CFRP tendons, prestressed steel strands) and other methods were conducted by R. Timothy Ball [6], S. Rahman [7], Michael K. Kenny [8], Michael Ambroziak [9], Mehdi S. Zarghamee [10,11], Dou Tiesheng [12] and Raafat EL-Hacha [13]. The significant advantage of the external reinforcement is that it is unnecessary to take the deteriorating pipes out of service. Moreover, it is able to actively compensate for the prestress loss caused by the broken prestressing wires [7]. The steel strand is able to fully exert the characteristics of the prestressed steel strand, such as a high tensile strength, and does not decrease with an increase in the bending angle. The well-known large-scale application of the external prestressed strands is the Great Man-Made River pipelines in Libya [14]. The GMR represents around $4000 \mathrm{~km}$ of pipes and most of them are $4.20 \mathrm{~m}$ internal diameter. In 1999, GMR faced some pipe bursts due to a highly corrosive environment. The authority immediately organized a way to proceed with repair of critical pipes with additional external post tensioning. The typical cycle for one pipe repair is 6 days (plus 2 days for a special pipe) in this project. Some operations can be fulfilled simultaneously to shorten the time cycle during the peak period. The significant advantage of this reinforcement is that it is unnecessary to take the deteriorating pipes out of service. This is significant for the water supply and other associated social issues. This reinforcement technology is a cost-effective way to ensure long-term service of the pipes with broken wires. However, few experimental studies have been carried out in the strengthening effect of the external prestressed strands on PCCP.

To evaluate the strengthening effect of external prestressed steel strands on $\mathrm{PCCP}$, a prototype test under variable internal water pressure was conducted for a prototype PCCP. The strains of the concrete core, prestressing wires and strands before and after the reinforcement were monitored in real time and then analyzed. The structural behaviors of the pipe and the strengthening effect of the method are discussed in this paper. 


\section{Test Scheme}

\subsection{Test Materials}

\subsubsection{Prestressed Concrete Cylinder Pipe (PCCP)}

The structure of the PCCPE adopted in this test is depicted in Figure 2. PCCPE is a composite structure pipe, and consists of a concrete core, a steel cylinder embedded in the concrete core, high-strength prestressing wires helically wrapped around the external concrete core and a mortar coating applied to the exterior of the pipe. Table 1 provides several key parameters of the PCCP. The inner diameter and the thickness of the concrete core are $2000 \mathrm{~mm}$ and $140 \mathrm{~mm}$, respectively. The length of the test pipe is $5000 \mathrm{~mm}$. Prestressing wires with $22.1 \mathrm{~mm}$ spacing between each wire, whose diameter is $6 \mathrm{~mm}$, are utilized. The working value of the water pressure is $0.6 \mathrm{MPa}$, and the design value is $0.6 \mathrm{MPa}+0.276 \mathrm{MPa}=0.876 \mathrm{MPa} \approx 0.9 \mathrm{MPa}$ (refer to ANSI/AWWA C304 [15]).

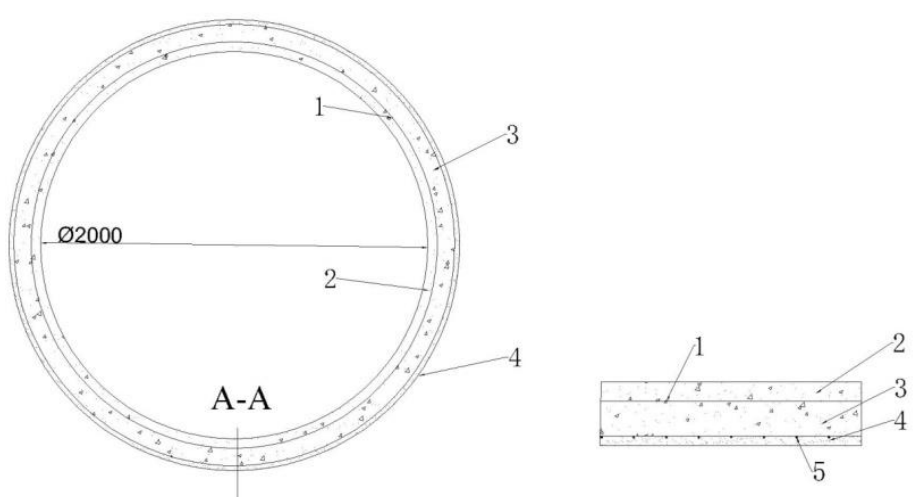

(a) Radial sectional view

(b) Partial enlarged view of section A-A

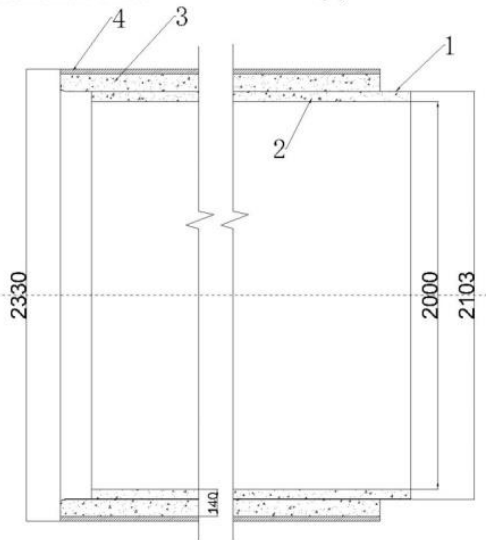

(c) Axial sectional view

Figure 2. The structural drawing of a PCCPE: 1 -Cylinder; 2 -Inner concrete core; 3 -Outer concrete core; 4-Mortar; 5-Prestressing wires; Dimension: $\mathrm{mm}$.

Table 1. Key parameters of the tested PCCP.

\begin{tabular}{|c|c|c|c|}
\hline Key Parameters & Values & Key Parameters & Values \\
\hline Inner diameter of $\mathrm{PCCP} / \mathrm{mm}$ & 2000 & $\begin{array}{l}\text { Standard compressive strength of } \\
\text { concrete } /\left(\mathrm{N} / \mathrm{mm}^{2}\right)\end{array}$ & 55 \\
\hline Thickness of core concrete $/ \mathrm{mm}$ & 140 & Modulus of concrete/(N/mm²) & $2.786 \times 10^{4}$ \\
\hline Inner diameter of cylinder $/ \mathrm{mm}$ & 2100 & $\begin{array}{l}\text { Standard compressive strength of } \\
\text { mortar } /\left(\mathrm{N} / \mathrm{mm}^{2}\right)\end{array}$ & 45 \\
\hline Thickness of cylinder/mm & 1.5 & Modulus of mortar $/\left(\mathrm{N} / \mathrm{mm}^{2}\right)$ & $2.535 \times 10^{4}$ \\
\hline Diameter of wires $/ \mathrm{mm}$ & 6 & Modulus of cylinder/(N/mm²) & $2.069 \times 10^{5}$ \\
\hline Spacing between each wire $/ \mathrm{mm}$ & 22.1 & Modulus of wire $/\left(\mathrm{N} / \mathrm{mm}^{2}\right)$ & $1.93 \times 10^{5}$ \\
\hline
\end{tabular}




\subsubsection{Steel Strand}

The strand adopted in the test is $1 \times 7-15.20-1860$ (refer to ISO 6934-4:1991, Steel for the prestressing of concrete-Part 4: Strand, NEQ). It is a non-bonded prestressed steel strand with double polyethylene cables, as illustrated in Figure 3. The nominal diameter and the nominal tensile strength of the strands are $15.2 \mathrm{~mm}$ and $1860 \mathrm{MPa}$, respectively (Table 2). The epoxy coating is applied to the base material of the strand at the fabrication stage, which provides a layer of protection against corrosion. There are double polyethylene cables (PE) outside the strand to ensure the strand's corrosion resistance property. In addition, the double polyethylene cables are filled with anti-corrosive grease of $\geq 50 \mathrm{~g} / \mathrm{m}$ to achieve free sliding between PE1 and PE2 with low friction. In general, each strand is protected by three anti-corrosion barriers.

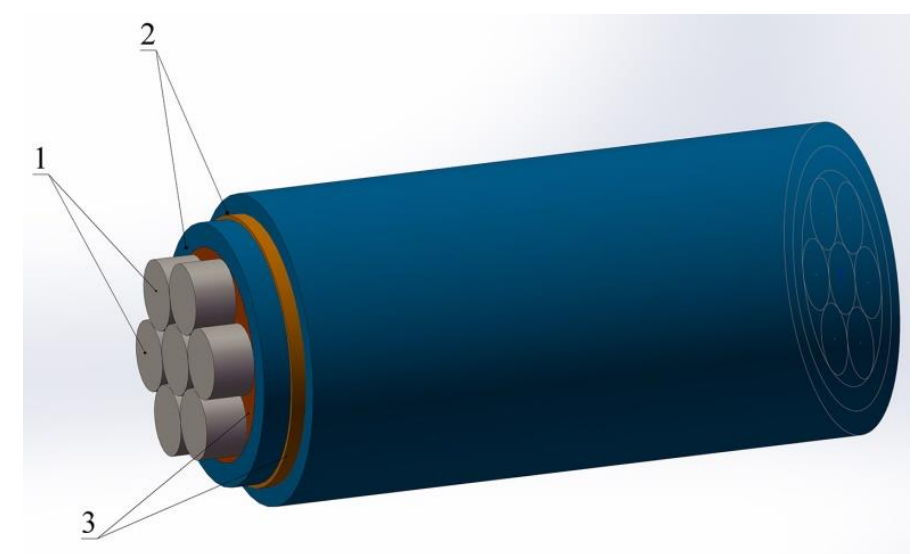

Figure 3. The structural drawing of steel strands: 1-Steel wires; 2 -Polyethylene cables; 3 -Grease.

Table 2. Key parameters of the adopted strands.

\begin{tabular}{cc}
\hline Key Parameters & Values \\
\hline Nominal diameter without $\mathrm{PE} / \mathrm{mm}$ & 15.2 \\
Nominal section area without $\mathrm{PE} / \mathrm{mm}^{2}$ & 140 \\
Nominal tensile strength $/\left(\mathrm{N} / \mathrm{mm}^{2}\right)$ & 1860 \\
Modulus $/\left(\mathrm{N} / \mathrm{mm}^{2}\right)$ & $1.95 \times 10^{5}$ \\
Coefficient of linear expansion $/\left(1 /{ }^{\circ} \mathrm{C}\right)$ & $1.2 \times 10^{-5}$ \\
Outer diameter with $\mathrm{PE} / \mathrm{mm}$ & 22 \\
\hline
\end{tabular}

As shown in Figure 4, a special anchorage system for two symmetrical hoop strands was invented for this test. The anchorage is specifically designed to avoid local punching forces on the pipe below the anchor body. Each anchorage can fix two strands and each strand wraps the pipe with two circles, which means that each anchorage can fix four circles of strands. The strands were wrapped externally outside the pipe with the $62 \mathrm{~mm}$ spacing between each strand according to the service water pressure and experience gained from Libya's work $[14,16]$. To mitigate border effects, the area strengthened with the prestressed strands is extended to the entire pipe. 


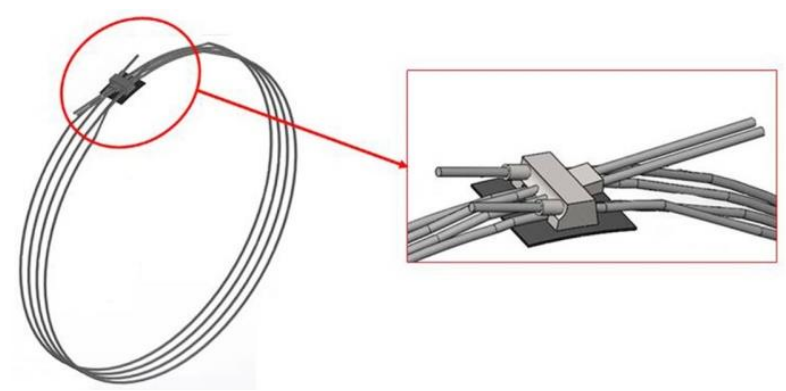

Figure 4. The system of each anchorage.

\subsection{Test Apparatus}

A prototype test was conducted in an assembled apparatus (Figure 5) and the apparatus was mainly constituted by two PCCPs and a fitting made of steel. The sealing design at the bell and spigot is pivotal in this test. Two sets of blind flanges with a bell and a spigot were adopted at both ends of the apparatus, and a rubber gasket was placed between the blind plate and the socket. It was necessary to inspect the entire device's water tightness property after the installation was completed.

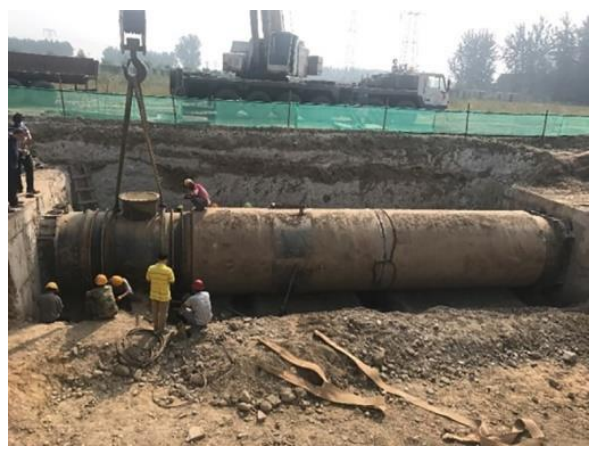

(a)

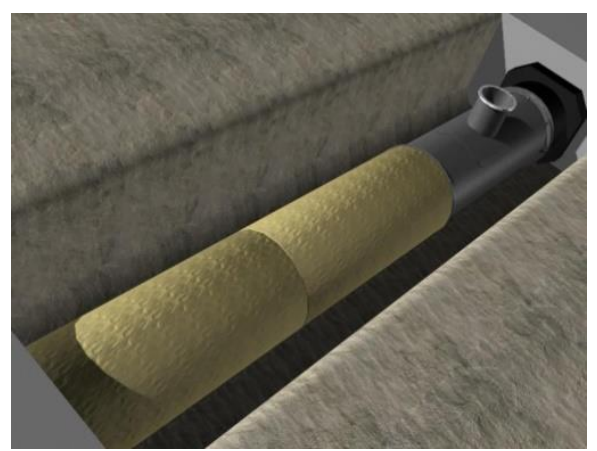

(b)

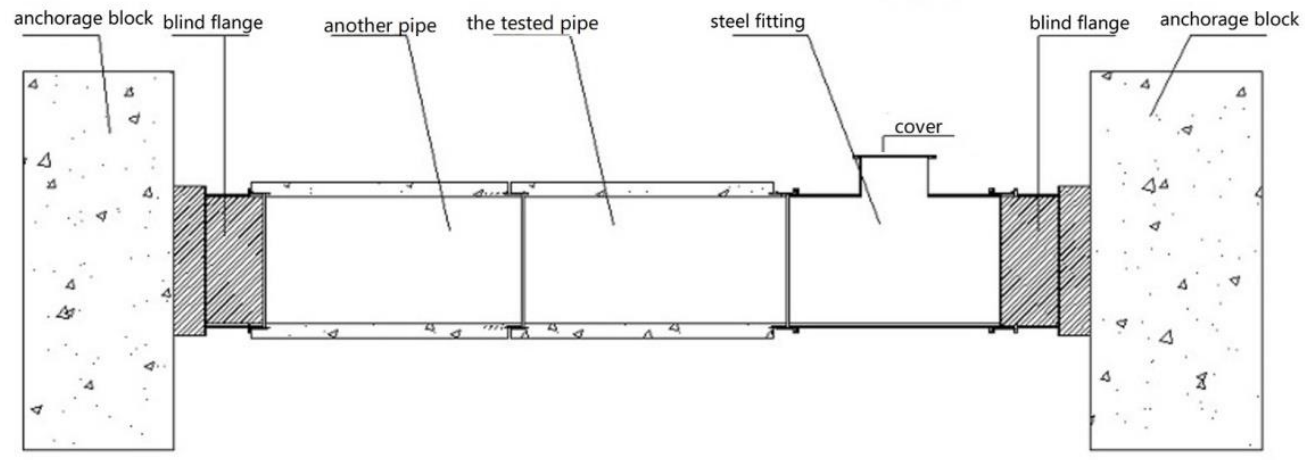

(c)

Figure 5. The schematic diagram of the test apparatus: (a) a spot photo; (b) design sketch in 3D; (c) design sketch in 2D.

\subsection{Test Procedures}

The entire test process (Figure 6) contains five load stages (I) increasing the internal water pressure to the working pressure $(0-0.6 \mathrm{MPa})$, (II) cutting the wires manually until the cracks propagate in the concrete core $(0.6 \mathrm{MPa})$, (III) decreasing the internal water pressure to the artesian pressure (0.6-0.2 MPa), (IV) performing the tensioning operation after wrapping the strands externally around 
the pipe $(0.2 \mathrm{MPa})$ and $(\mathrm{V})$ increasing the internal water pressure to the design value $(0.2-0.9 \mathrm{MPa})$. These five stages were divided into twenty-four steps, as shown in Table 3. A stepwise loading method was utilized to ensure the stability of the changing process of the internal water pressure. Each load stage is $0.1 \mathrm{MPa}$ and is maintained for $5 \mathrm{~min}$. A water bump was applied to provide an internal pressure of the apparatus. A pressure gauge and two pressure transmitters, MIK-P 300 (Manufactured by Asmik, Hangzhou, China), were respectively installed at the water inlet (as shown in Figure 7) to monitor the internal water pressure in real-time throughout the entire process. Cracks in the mortar and the outer concrete core were observed, and detailed information about the cracks including the position and width was recorded once visible cracks occurred. Three intermediate procedures of the wires breaking and the tensioning operation were chosen respectively considering that each operation contains several complex processes. Furthermore, it is critical to determine the position of broken point. In most of the actual pipe failures modes, most pipes fail at 4 or $8 \mathrm{o}^{\prime}$ clock, not at the invert, crown, or spring-lines [5]. The position of $8 \mathrm{o}^{\prime}$ clock was chosen in this test for convenience, as demonstrated in Figure 8.

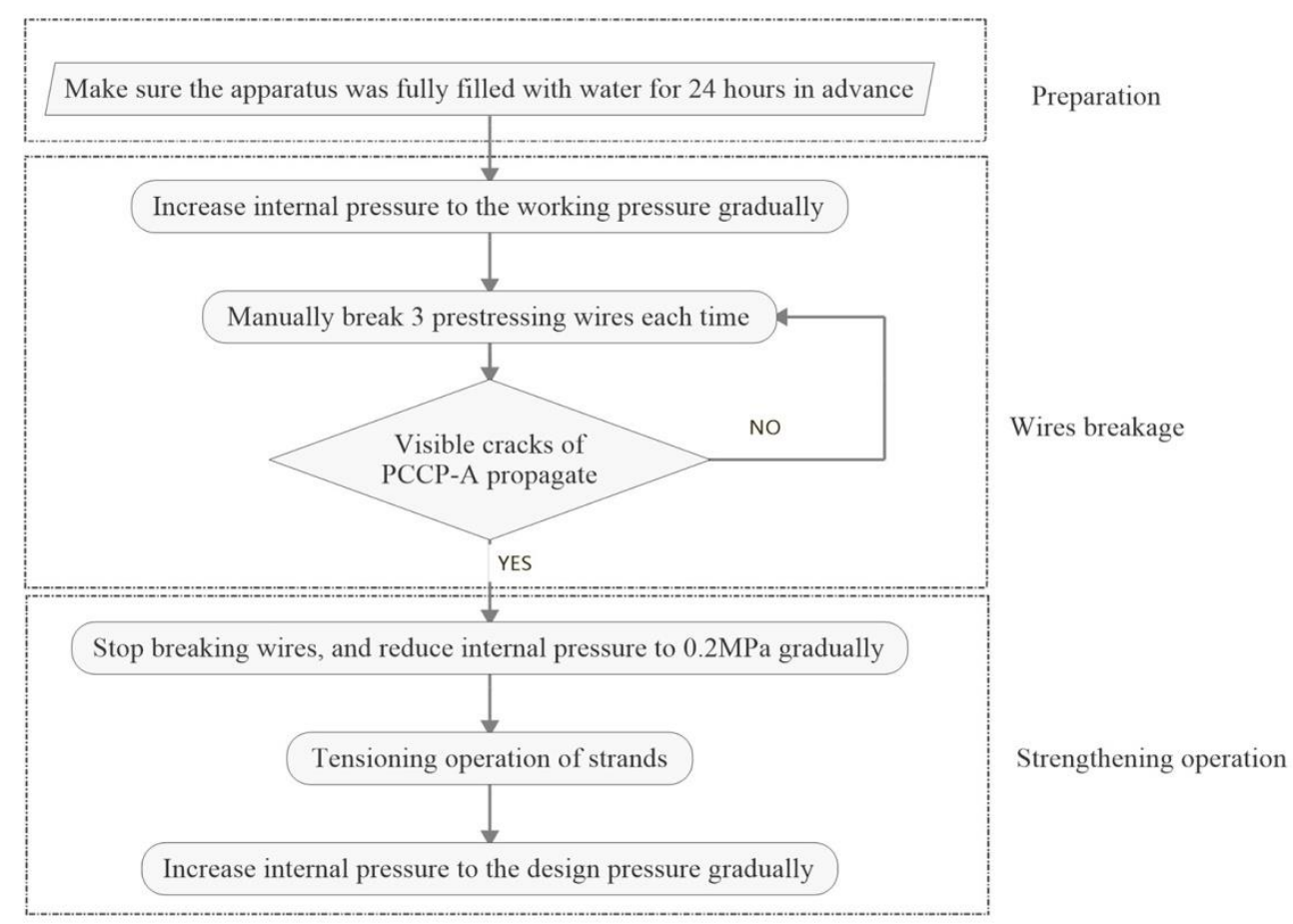

Figure 6. Load condition and load steps. 
Table 3. The entire procedure and load steps.

\begin{tabular}{cccc}
\hline Load Stage & Load Step & Details & $\begin{array}{c}\text { Internal Water } \\
\text { Pressure/MPa }\end{array}$ \\
\hline \multirow{4}{*}{ I } & 1 & Preparation & 0 \\
& 2 & & 0.1 \\
& 3 & & 0.2 \\
& 4 & Increase internal water pressre, hold for 5 min & 0.3 \\
II & 5 & & 0.4 \\
& 6 & & 0.5 \\
& 7 & Break prestressing wires manually until visible & 0.6 \\
III & 8 & cracks propagate. & 0.6 \\
& 9 & & 0.6 \\
& 10 & & 0.6 \\
IV & 11 & & 0.5 \\
& 12 & & 0.4 \\
& 13 & Decrease internal water pressre, hold for 5 min & 0.3 \\
& 14 & & 0.2 \\
& 15 & & 0.2 \\
V & 16 & & 0.2 \\
& 17 & & 0.2 \\
& 18 & & 0.3 \\
& 19 & & 0.4 \\
& 20 & Tensioning operation of steel strands & 0.5 \\
& 21 & & 0.6 \\
& 22 & & 0.7 \\
& 23 & & 0.8 \\
& 24 & & 0.9 \\
\hline
\end{tabular}

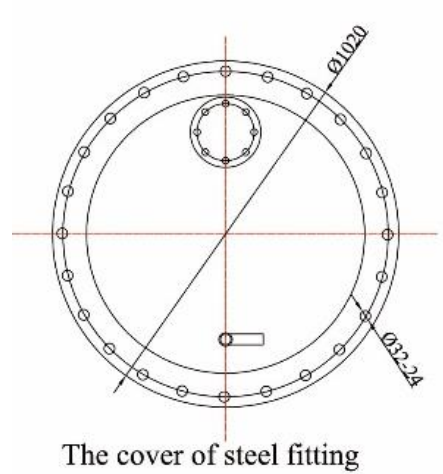

The cover of steel fitting

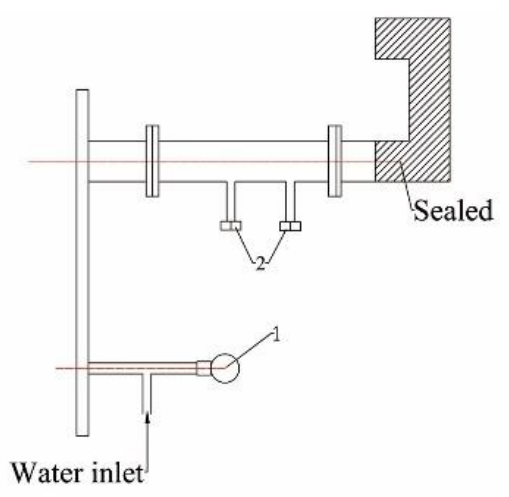

Water inlet

Figure 7. The location of pressure monitors: 1 -Pressure gauge; 2 -Pressure transmitter. 


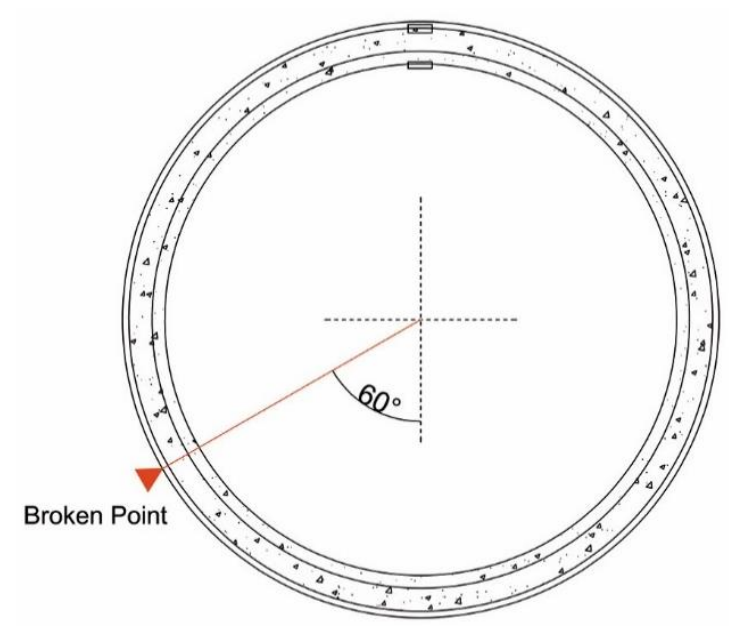

Figure 8. Location of the broken point.

Post-tensioning was designed with the consideration that tension limits in the area of the pipe lost the original prestress and compression limits in the area with an existing prestress were both satisfied. The design of tensile strength factor for strands is $0.63[17,18]$, indicating that the target tensile strength is equal to $1171.8 \mathrm{MPa}$. To prevent a prestress loss due to the retraction of clips and the stress relaxation of strands, excessive stretching is essential. The tensioning process is divided into six stages, which are $20 \%, 25 \%, 50 \%, 75 \%, 100 \%$ and $115 \%$. Tensioning is performed simultaneously from both sides and in a symmetrical manner along the pipeline axis (I-II-III) using two jacks, YD25-100, and two oil pumps, ZB4-500, as displayed in Figures 9 and 10.

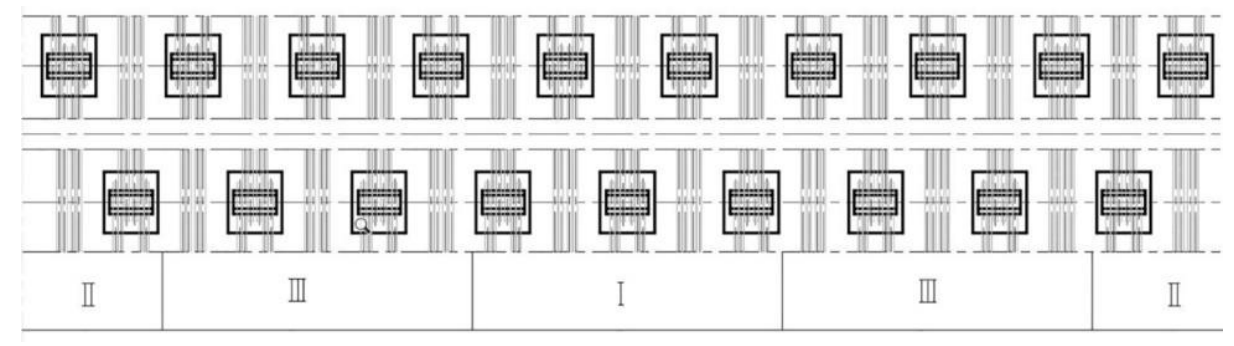

Figure 9. The sequence diagram of tensioning (I-II-III). 


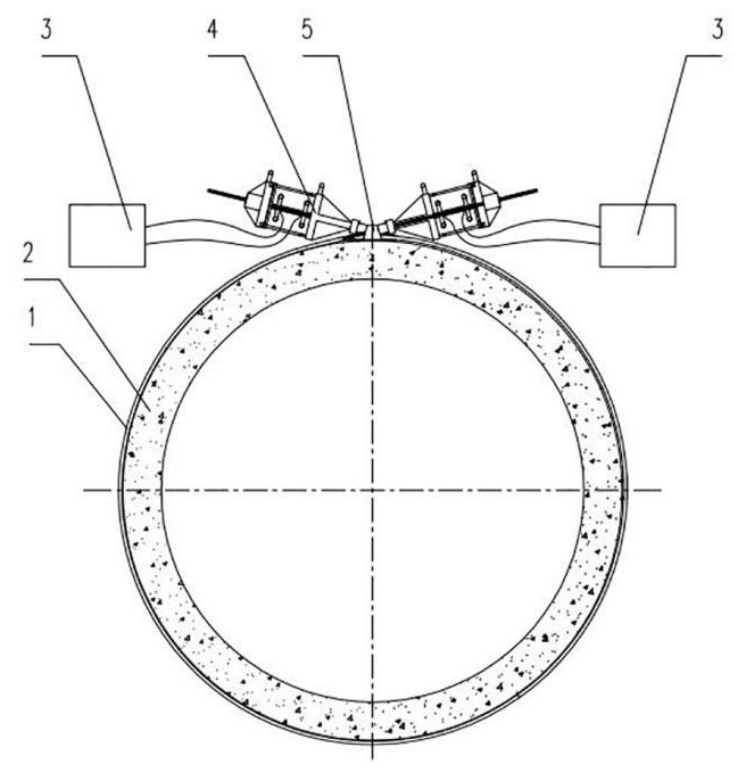

Figure 10. The schematic diagram of the tensioning system: 1-Strand; 2-PCCP; 3-Pump; 4-Jack; 5-Anchorage.

\subsection{Monitoring Content}

The monitoring contents of this test include the strains of the inner concrete core, external concrete core, prestressing wires and prestressed strands using resistance strain gauges with strong anti-interference abilities and high reliabilities.

Figure 11 illustrates the three monitoring sections of the test pipe along the axial direction. Section 1 (S1) stands for the section that is right in the middle of the wires breakage area. Section 2 (S2) is in the influencing area of wires breakage and Section 3 (S3) is in the area away from wires breakage. The strain gauges were installed on the inner surface of the concrete core, the outer surface of the concrete core and the prestressing wires at inverted $\left(360^{\circ}\right)$, crown $\left(180^{\circ}\right)$, and spring-line $\left(90^{\circ}\right.$, $270^{\circ}$ ) orientations.
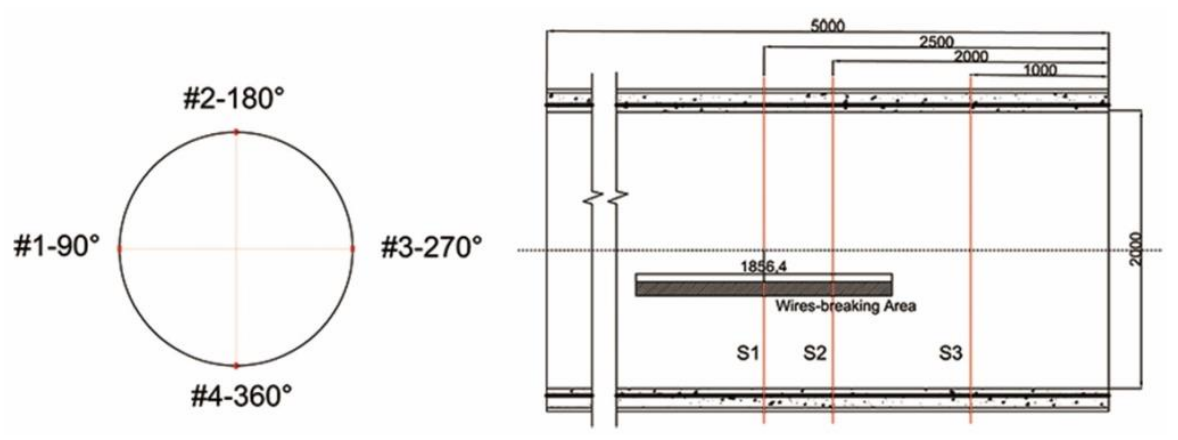

Figure 11. Location of measuring sections; dimension: $\mathrm{mm}$.

Double polyethylene cables locating around the measure points were removed for precision and convenience of measurement. The strain gauges were arranged on the surface of each strand wire at inverted $\left(360^{\circ}\right)$, crown $\left(180^{\circ}\right)$, and spring-line $\left(90^{\circ}, 270^{\circ}\right)$ orientations of Section 1 , as depicted in Figure 12. Taking the size of each component into consideration, the specification of the resistance strain gauge is $50 \times 3 \mathrm{~mm}, 10 \times 2 \mathrm{~mm}$ and $2 \times 1 \mathrm{~mm}$ for the concrete core, prestressing wires and the strands, respectively. 


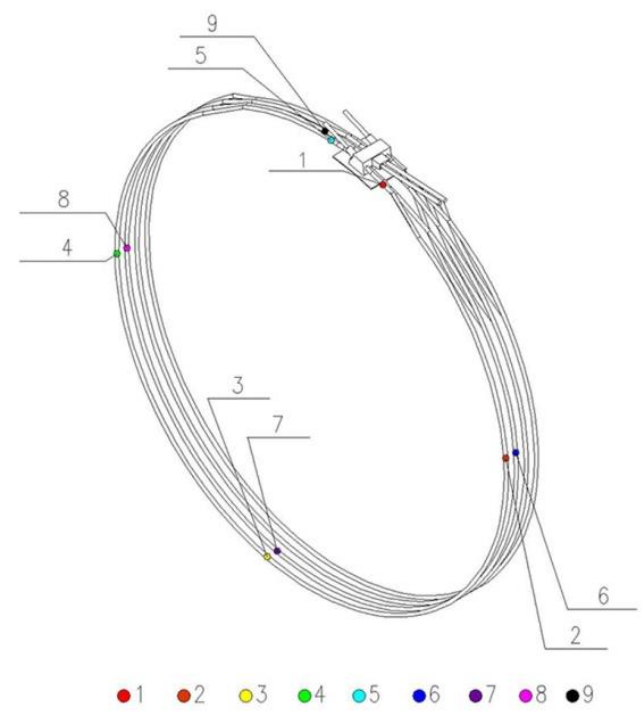

Figure 12. Arrangement of the measuring points for each strand wire.

Various approaches were utilized to ensure the strain gauges' efficiency. A visual inspection and resistance measurement of the strain gauges should be performed and the area where they are supposed to paste should be polished and cleaned carefully beforehand. A premix of bonding components A and B was applied to achieve the complete attachment between the surface of the gauges and the measured surface. After attaching, the conductors should be soldered and fixed. Polyurea was utilized to guarantee the property of waterproofing, considering that the strain gauges may fail once they are in contact with water.

All data were collected automatically through a data acquisition system, LDS data acquisition instrument, as shown in Figure 13. All devices had been reset before the start of the test.

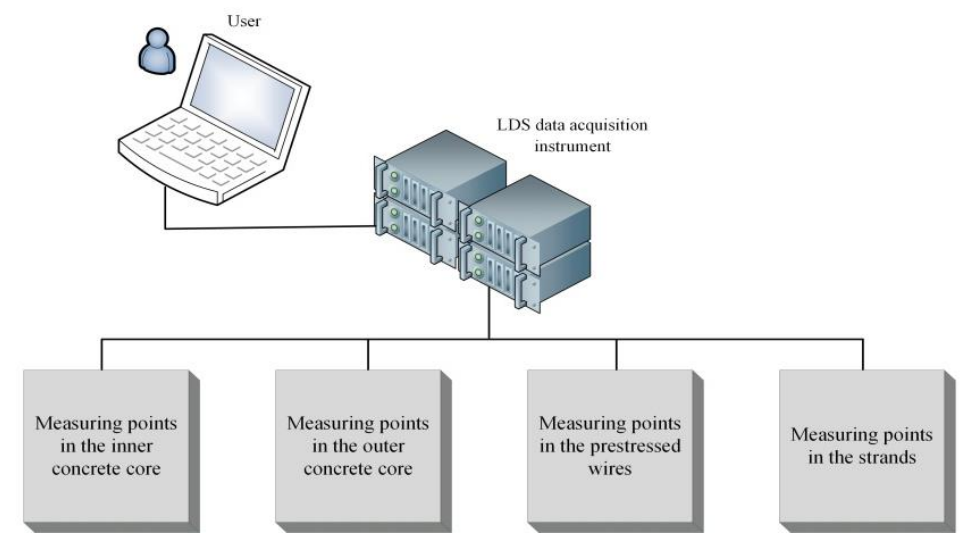

Figure 13. Data acquisition system.

\section{Test Results and Discussion}

\subsection{Results Revised}

Hoop compressive strains were produced in the core concrete owning to the contribution of the prestress applied by prestressing wires. Therefore, the hoop tensile strain caused by internal water pressure in each component of the PCCP will be balanced by the compressive prestrain. In other words, only when the tensile strain is larger than the compressive prestrain will the real tensile strain be measured. Therefore, the real strain state of the core concrete and prestressing wires should be revised by the following equation:

$$
\varepsilon_{r}=\varepsilon_{i}+\varepsilon_{m}
$$


where $\varepsilon_{r}$ is the real strain of the component, $\varepsilon_{i}$ is the initial prestrain caused by prestress, $\varepsilon_{m}$ is the strain measured by strain gauges. Moreover, positive values represent the tensile strain and negative values represent the compressive strain.

According to ANSI/AWWA C304-2014 [15], the state of stress with a single layer of prestressing is calculated by the following equations.

The initial prestress in the core concrete:

$$
f_{i c}=\frac{A_{s} f_{s g}}{A_{c}+n_{i} A_{s}+n_{i}^{\prime} A_{y}}
$$

The initial prestress in the prestressing wire:

$$
f_{i s}=-f_{s g}+n_{i} f_{i c}
$$

The final prestress in the concrete:

$$
f_{c r}=\frac{f_{i c}\left(A_{c}+n_{r} A_{s}+n_{r}^{\prime} A_{y}\right)-\left(A_{s} E_{s}+A_{y} E_{y}\right) s-A_{s} R f_{s g}}{A_{c}+\left(n_{r} A_{s}+n_{r}^{\prime} A_{y}\right)(1+\varphi)}
$$

The final prestress in the prestressing wire:

$$
f_{s r}=f_{i s}+R f_{s g}+\frac{A_{c}\left(f_{i c} \varphi n_{r}+E_{s} s\right)-R A_{s} f_{s g} n_{r}(1+\varphi)}{A_{c}+\left(n_{r} A_{s}+n_{r}^{\prime} A_{y}\right)(1+\varphi)}
$$

The final prestrain in the concrete:

$$
\varepsilon_{c r}=\frac{f_{c r}}{E_{c}}
$$

The final prestrain in the prestressing wire:

$$
\varepsilon_{s r}=\frac{f_{s r}}{E_{s}}
$$

where

$A_{s}$ - total area of prestressing wire $\left(\mathrm{mm}^{2} / \mathrm{m}\right)$,

$A_{c}$-core concrete area (including steel-cylinder area, $\mathrm{mm}^{2} / \mathrm{m}$ ),

$A_{y}$-steel cylinder area $\left(\mathrm{mm}^{2} / \mathrm{m}\right)$,

$f_{s g}$ - gross wrapping stress in prestressing wire (MPa),

$n_{i}, n_{r}$-modular ratio of prestressing wire to core concrete at wrapping and at maturity,

$n_{i}^{\prime}, n_{r}^{\prime}$-modular ratio of steel cylinder to core concrete at wrapping and at maturity,

$E_{c}, E_{s}, E_{y}$-design modulus of elasticity of core concrete, prestressing wires and steel cylinder,

$\mathrm{s}$-design shrinkage strain for a buried pipe,

$\varphi$-design creep factor for a buried pipe,

$R$-wire-relaxation factor for a single layer of prestressing.

The compressive prestrain in the core concrete caused by prestress is $-227 \times 10^{-6}$. The tensile prestrain of prestressing wires is $4492 \times 10^{-6}$. It should be noted that the data recorded were all revised and the strains given in this paper are the real strains of each component.

To assess the state of the PCCP, the onset of micro-cracking in the concrete core is when the strain of core concrete [15] reaches $1.5 \varepsilon_{t}^{\prime}=1.5 \times \frac{0.52 \sqrt{f_{c u, k}}}{E_{c}}=207 \times 10^{-6}$, where $\varepsilon_{t}^{\prime}$ and $f_{c u, k}$ represents the elastic strain when the stress of the core concrete reaches the design value of tensile strength, and the standard compressive strength of core concrete in $\mathrm{N} / \mathrm{mm}^{2}$, respectively. Moreover, the standard compressive strength of core concrete, $\mathrm{f}_{\mathrm{cu}, \mathrm{k}}$, is equal to $1.25 \cdot \mathrm{f}_{\mathrm{c}}^{\prime}$, in which $\mathrm{f}_{\mathrm{c}}^{\prime}$ stands for the design 28-days 
compressive strength of core concrete in American Society for Testing Materials(ASTM) [19]. Once the strain reaches $11 \varepsilon_{t}^{\prime}=1522 \times 10^{-6}$, visible cracks are likely to appear.

\subsection{Prestressing Wires}

Figure 14 exhibits the hoop strain in the prestressing wires of Section 1 (Figure 14a), Section 2 (Figure 14b) and Section 3 (Figure 14c) with continuous load steps. The strains of Sections 1 and 2 changed obviously with the wires breaking, while the strains of the prestressing wires away from the wires breakage area (S3) did not show evident variation.

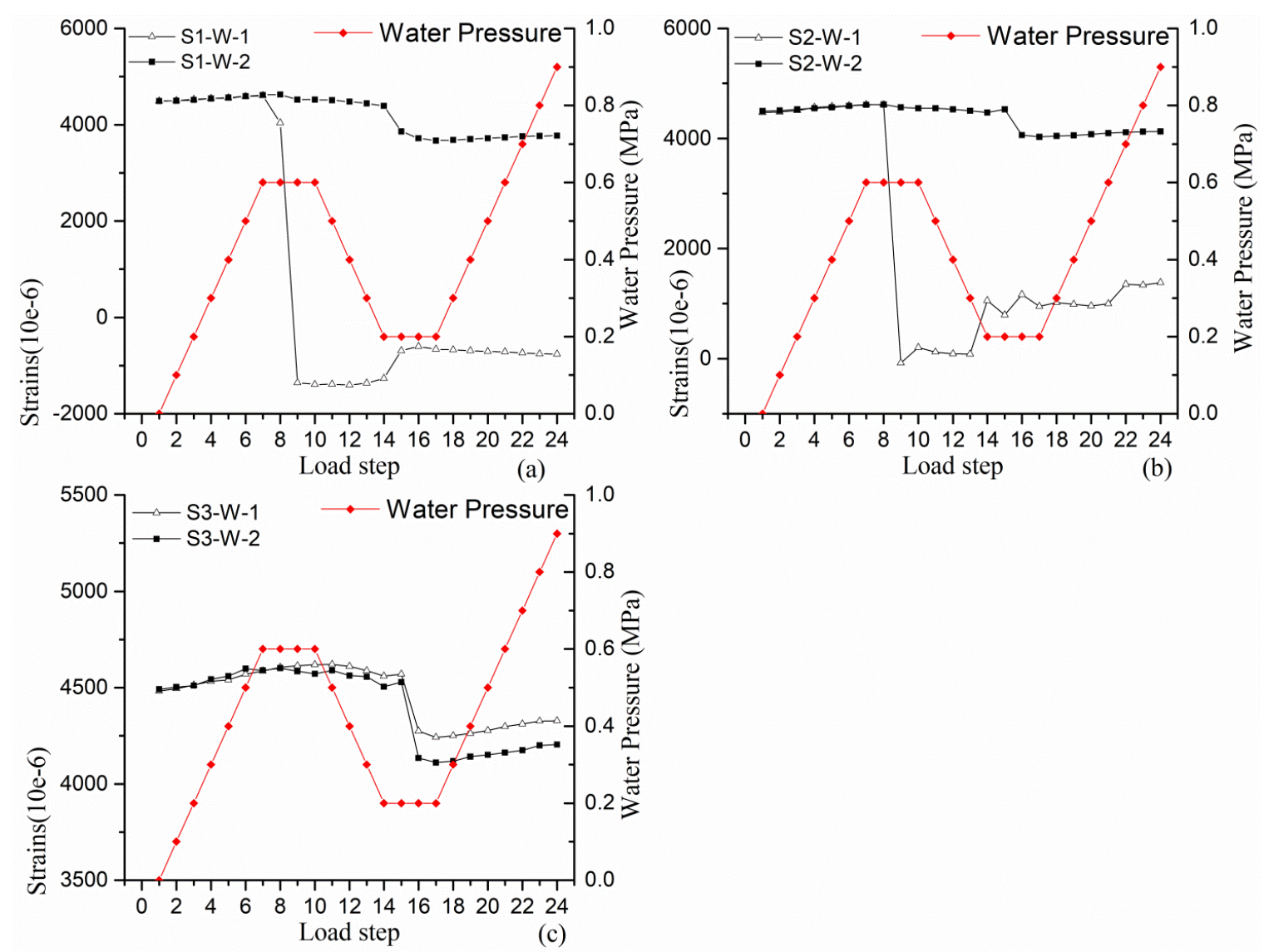

Figure 14. The strain curves of prestressing wires: (a) Section 1; (b) Section 2; (c) Section 3.

The increase in the internal water pressure has little impact on the strains of Sections 1 and 2 during the first load stage (load stage I). The structural integrity was in a good condition and the concrete core took primary responsibility of sustaining the internal water pressure. Moreover, the strains at measuring point \#1 of each section were nearly equal to \#2, indicating that the stress in the prestressing wires was uniform before breaking wires.

When the operation of wires breakage (load stage II) finished, the strains at measuring point \#1 reflected a drastic drop owning to the abrupt loss of prestress. The strain of measuring point \#2 at the crown only decreased to some extent. This phenomenon reveals that the mortar coating's bonding quality with wires was in a good state. Consequently, the prestress of wires resumed beyond a certain length from the broken point, which is in accordance with the conclusion summarized by Ge. S.W. [5]. After the tensioning operation of strands, the tensile stress of prestressing wires declined to some extent considering that the responsibility of supplying the tensile strength was shared by the prestressing wires and the steel strands.

It is worth mentioning that the target tensile strength of strands (Mentioned in 2.1.2) is determined on the condition that the prestress of the wires after breakage is fully removed. However, as depicted 
in Figure 14, the actual prestress loss of the broken wires existed within a certain length and the strains of wires beyond a certain length decreased to some extent, which is not zero. This phenomenon indicates that it is conservative and safe to determine the target tensile strength of strands based on the former assumption.

\subsection{Concrete Core}

Figure 15 presents corresponding strains in the inner core concrete of Section 1 (Figure 15a), Section 2 (Figure 15b), the outer core concrete of Section 1 (Figure 15c), Section 2 (Figure 15d) and Section 3 (Figure 15e). A growth in the internal water pressure linearly increased the strains in the inner core concrete and the outer core concrete during the initial load stage (load stage I). The strains at crown, invert and spring-line orientations of core concrete, no matter inner or outer core concrete, were almost equal. Meanwhile, the strains all show negative values owning to the contribution of the prestressing wires, which means that the concrete core was still under compression. There was no crack initiation in the concrete core surface in this load stage.
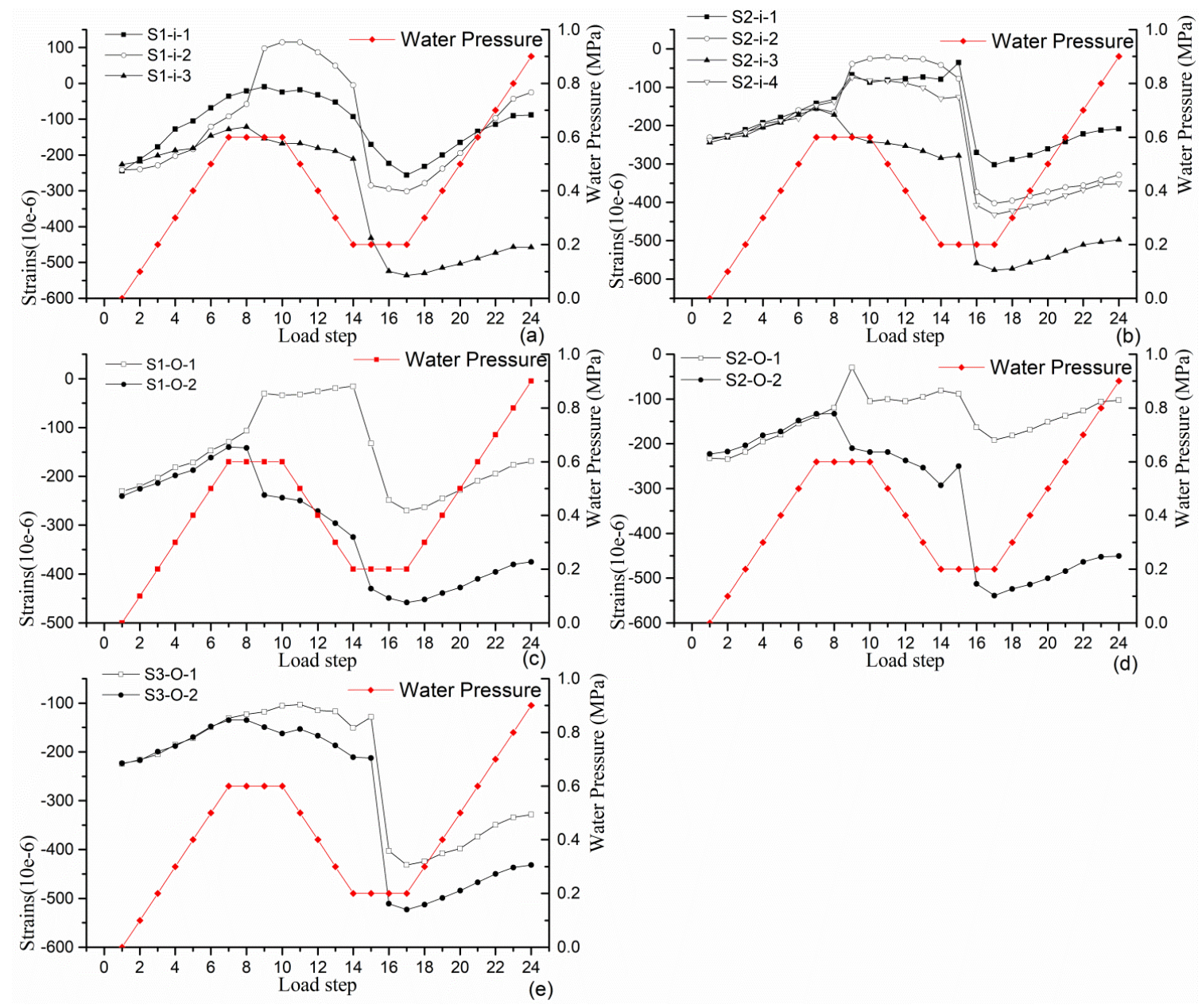

(d)

Figure 15. The strain curves of core concrete: (a) Section 1 of inner concrete core; (b) Section 2 of inner concrete core; (c) Section 1 of outer concrete core; (d) Section 2 of outer concrete core; (e) Section 3 of outer concrete core.

The strain in the core concrete changed non-linearly as the percentage of broken wires increased during load stage II. A rapid rising in the strains of each section, except for Section 3 in the outer concrete core, appeared when the percentage reached a certain degree due to the abrupt prestress loss.

The strain in the inner core concrete at the crown of each section showed a greater magnitude of change than the invert and spring-line as the percentage of broken wires increased. Taking Section 1 
for example, the strain at crown turned to be a tensile strain at load step 9 while strains at invert and spring-lines were still compressive. This phenomenon reveals that breaking of the wires has the most influence on the crown than the invert and spring-line of inner concrete core. The strains at measuring point \#1 and \#3 of each section show a slight distinction although they were both located at the spring-line in the inner concrete core. The strain at \#1 showed a sudden increase while the strain at \#3 suddenly decreased to some extent during the operation of wires breakage, as depicted in Figure 15a,b. The abrupt rupture of prestressing wires can induce instantaneous stress relief around the broken points (between \#1 and \#4, anticlockwise, near \#1) and stress localization away from the broken points (between \#2 and \#3, clockwise, near \#3). Consequently, the strains at the spring-line of each section in the inner core concrete are not completely identical. Different from the phenomenon in inner core concrete, the strain at spring-line was larger than the crown in outer core concrete, as illustrated in Figure $15 \mathrm{c}-\mathrm{e}$. The operation of wires breakage greatly impacts on the strain at the spring-line near the broken points in the outer concrete core. In addition, as exhibited in Figure 15e, Section 3 in the outer concrete core showed a slight variation in strain, suggesting that breaking wires manually performed no remarkable influence on the area away from wires breakage.

Visible cracks on the surface of the mortar coating first occurred at the pipe spring-line when the percentage of broken wires was up to $20.18 \%$ through field observation. An increase in the percentage of broken wires accelerated the crack propagation in the mortar coating. Cracks were soon found in outer concrete core at the pipe spring-line which was closer to the broken point (as shown in Figure 16a). They propagated rapidly along the longitudinal direction as the percentage of broken wires increased and induced several branches gradually. New cracks occurred simultaneously when the former cracks extended, which formed a crack band together. The appearance of these cracks intensified the damage of the pipe structure and made the pipe unable to sustain any tensile stress. Interfacial debonding between the mortar coating and outer concrete core was discovered at the spring-line (Figure 16b). Meanwhile, a loud sound was heard, which may be induced by the cracking of concrete core. The maximum width of cracks in the outer concrete core at the spring-line was $2.2 \mathrm{~mm}$ via field observation, as plotted in Figure 17.

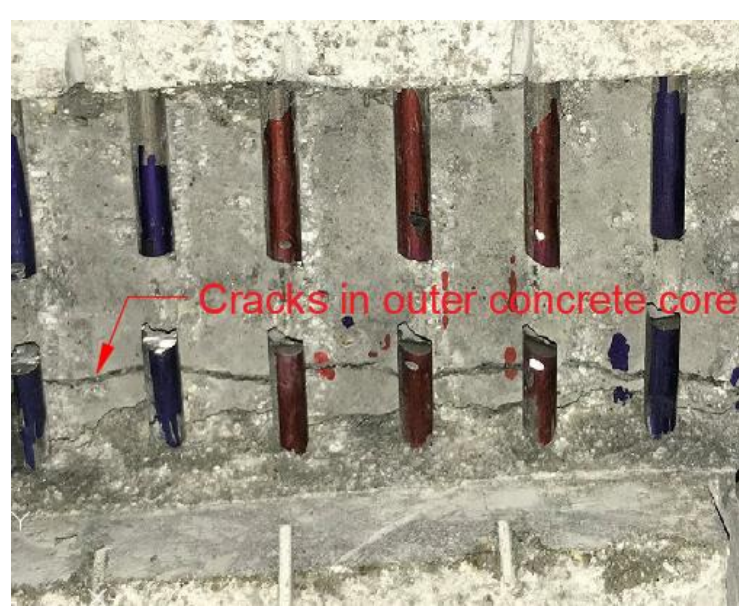

(a) Cracks distribution in outer concrete core

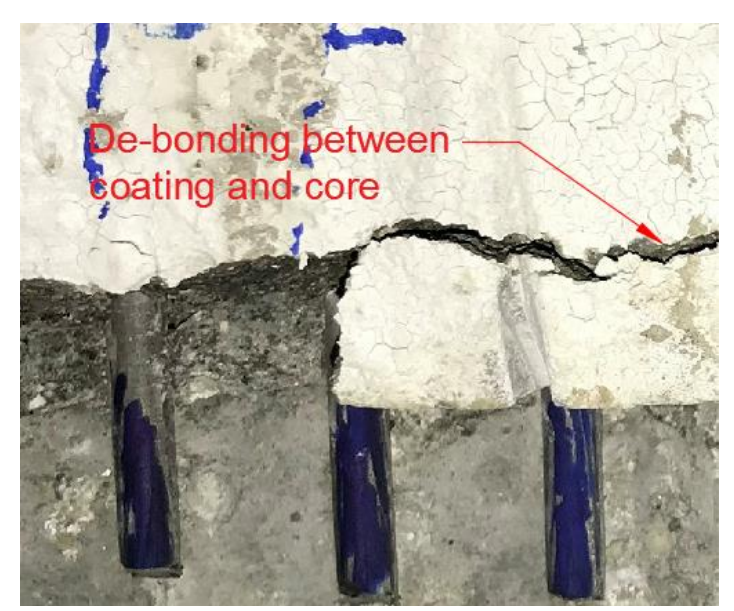

(b) De-bonding between coating and core

Figure 16. Phenomena of test pipe after wire breakage. 


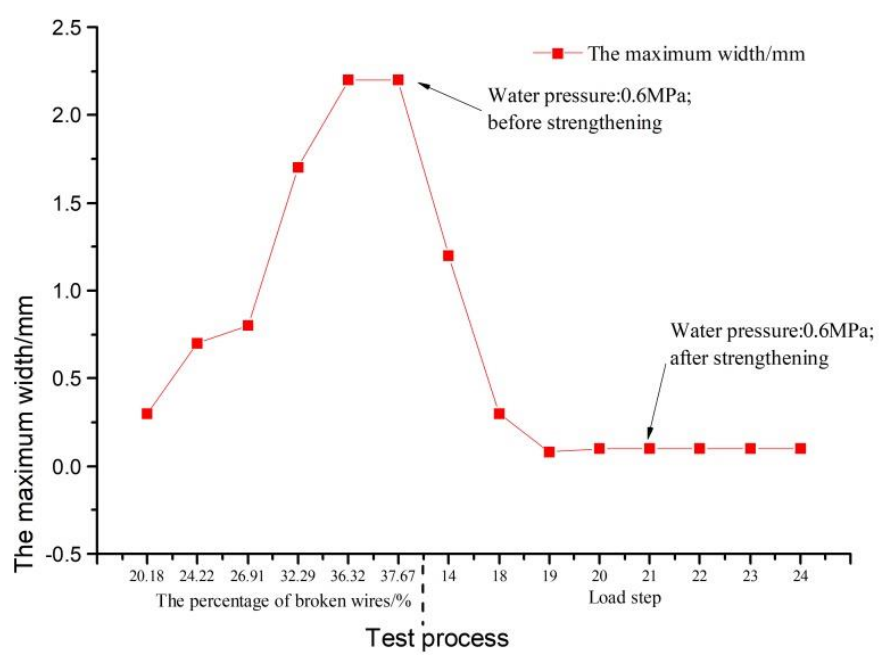

Figure 17. The change of maximum width of cracks in the outer concrete core.

After the operation of wire breakage, the subsequent load stage (load stage III) decreased the internal water pressure to the artesian pressure $(0.2 \mathrm{MPa})$. The strains in the core concrete showed a decline with the water pressure decreasing, apart from the measuring point \#1 in the outer concrete core. The occurrence of cracks and the dynamic changes of the internal water pressure led to the redistribution of the stress in the test pipe. As a result, the strain in \#1, which was at the spring-line around the broken point in the outer concrete core and in the area where cracks were densely distributed, showed a slight rise in this load stage. On the basis of field records, the micro-cracks in the concrete core and mortar coating displayed a slight closure. However, the maximum width of cracks in the outer concrete core at the spring-line was still $1.2 \mathrm{~mm}$.

The fourth load stage was the tensioning operation of the strands. Some fluctuation appeared on the strain curves of the core concrete, due to the stepwise tensioning and some inevitable artificial disturbance. In general, the overall changing tendency of the strains in the core concrete was evident. The strains in the core concrete all showed a drastic drop during the process of tensioning. The maximum width of cracks in the outer concrete core at the spring-line was reduced from the former $1.2 \mathrm{~mm}$ to $0.1 \mathrm{~mm}$ (Figure 17). Most visible cracks show a closure property and are eventually difficult to find.

The final load stage (load stage V) involved increasing the water pressure again until the pressure reached the design value, aiming to verify the strengthening effect of the external strands. The comparison of the strain in each section of the core concrete before and after the tensioning operation was given in Figure 18. The strain of each measuring point when the water pressure was again up to $0.6 \mathrm{MPa}$ was far lower than the strain before strengthening. Although the strain at each measuring point showed a slight growth with the continuing increase in water pressure till load step 24 , the strain level was still much lower than the level when load step 10 finished. The maximum width of the cracks in the outer concrete core at spring-line almost remained invariant at approximately $0.1 \mathrm{~mm}$ as the pressure increased. This phenomenon indicates that the prestressed strands can not only constrain the crack propagation, but also actively restore the prestress loss due to the wires breakage. In addition, the concrete core was restored to be compressive again. The water tightness of test pipe was still in a good situation according to the field observation. 


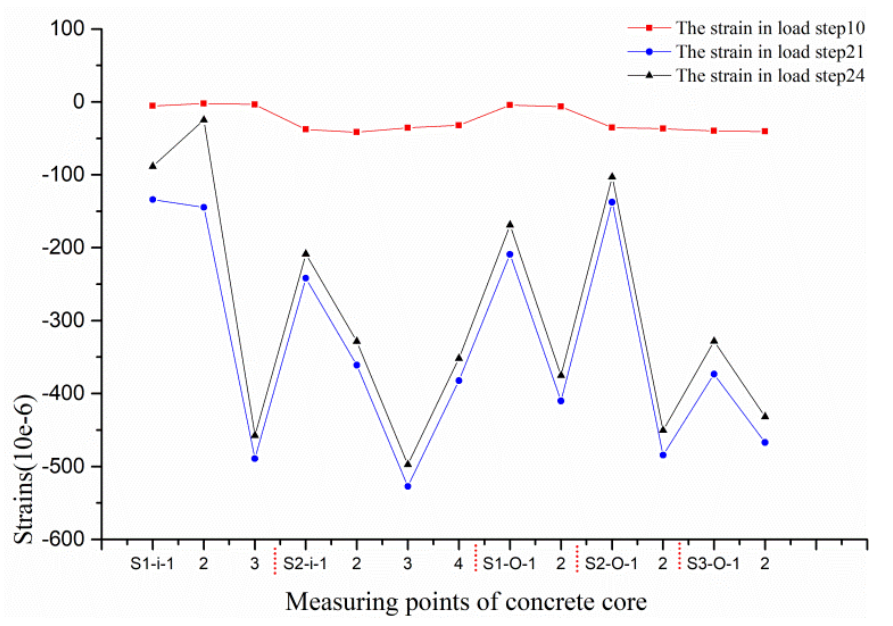

Figure 18. Comparison of the strain before and after the tensioning operation.

The strains of the core concrete were all no more than $207 \times 10^{-6}$, which means that the cracks did not pass through the areas where the measuring points are attached when they propagate. Although the strain gauges did not capture the initiation and propagation of cracks, the values of the strain gauges are still able to reflect the actual overall condition of the test pipe.

\subsection{Prestressed Strands}

The actual situation of strands hopped on the distress pipe is as demonstrated in Figure 19. Figure 20 gives the strains of each measuring point in the prestressed strands. Due to the strand's low coefficient of friction and high force transmission properties, the prestress force is theoretically efficiently transferred along the entire 360-degree pipe circumference. However, the factors that can cause prestress loss of the strand involve the friction resistance between the strands and the pipe, the anchor deformation, the retraction of clips and the concrete elastic compression induced by stepwise tensioning etc. These factors comprehensively influence the stress distribution in the strand.

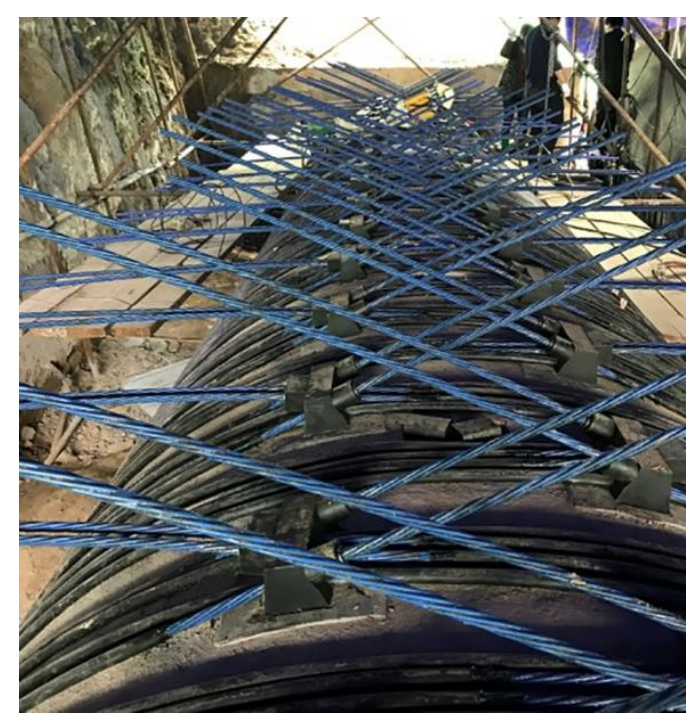

Figure 19. A spot photo of the test pipe after tensioning. 


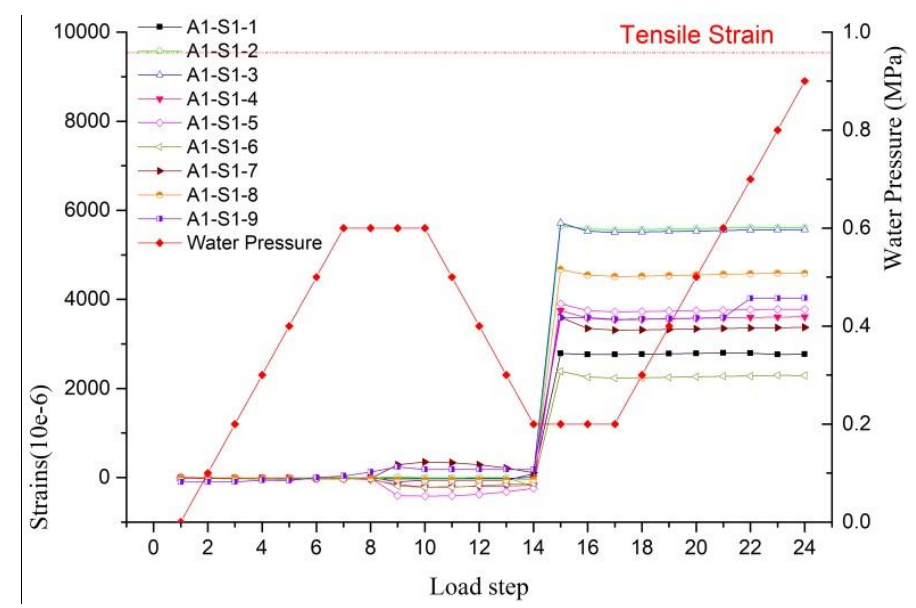

Figure 20. The strain curves of prestressed strands.

The nominal tensile strain $\varepsilon_{s}$ is calculated by the following equation:

$$
\varepsilon_{s}=\frac{\sigma_{s}}{E_{s t}}=\frac{1860 \mathrm{MPa}}{1.95 \times 10^{5} \mathrm{~N} / \mathrm{m}^{2}}=9538.46 \times 10^{-6}
$$

The strains of measuring points in Figure 20 were all below the tensile strain level. The hoop strand did not yield after the tensioning operation. In addition, it can be inferred that other unmeasured strands do not yield as well, since the measured strand was in the most unfavorable section of the pipe. It is noted that the prestress loss in the strand does not decrease lineally or symmetrically, since the measuring points were not located on the same wire of the total seven wires in each strand due to the restriction of the field condition.

\section{Conclusions}

A prototype test was performed to investigate the strengthening effect of external prestressed steel strands on a PCCP. Based on the test results, the following conclusions can be drawn:

(1) The strains in prestressing wires showed slight variation with the change of internal water pressure during the entire process. Breakage of the wires leads to significant prestress loss within a certain distance from the broken point. The prestress resumes partially beyond a certain length due to the bond quality of the mortar coating with the prestressing wires.

(2) The operation of breaking wires mostly affected the strains of the inner concrete at the crown. It significantly influenced the outer concrete core at spring-line which is near the broken point. The onset of visible cracks in the outer concrete core first appeared at spring-line near the broken point. The debonding between mortar coating and outer concrete core was found at the same position according to the observations.

(3) After the tensioning operation of the strands, the strands contribute to compensate for the prestress loss induced by the wires breakage. The crack propagation in the core is also constrained by the strands simultaneously. The test pipe was able to sustain the design internal water pressure after strengthening and the water tightness property was in a good condition. In addition, the maximum width of the cracks in the outer concrete core at the spring-line was reduced from the $1.2 \mathrm{~mm}$ to $0.1 \mathrm{~mm}$ because of the contribution of the strands. The effect of PCCP strengthened with external prestressed strands is evident.

(4) The strains of the steel strands were all below the tensile strain level. The method of PCCP strengthened with the external prestressed strands is able to meet the strengthening requirement of the test and is an effective method for strengthening PCCP. The study presented in this paper lays the groundwork for future research into the reinforcement of PCCP with external prestressed steel strands. 
Author Contributions: Conceptualization, T.D., S.X. and L.Z.; Methodology, T.D. and L.Z. and B.C.; Software, T.D. and L.Z.; Writing-Original Draft Preparation, L.Z.; Writing-Review and Editing, B.C., X.L. and M.L.; Funding Acquisition, J.Y. and Q.Z.

Funding: This research was supported by the Beijing south-to-North water Transfer Line management Office (GXGLC-JSZX -2017-CG01), the National Natural Science Foundation of China (Grant No. 5097911), Beijing Municipal Science and Technology Commission (Z141100006014058) and China Institute of Water Resources and Hydropower Research (SM0145B632017).

Acknowledgments: The authors would like to thank the anonymous reviewers for their constructive suggestions to improve the quality of the paper.

Conflicts of Interest: The authors declare no conflict of interest.

\section{References}

1. Ge, S.Q.; Sinha, S. Failure Analysis, Condition Assessment Technologies, and Performance Prediction of Prestressed-Concrete Cylinder Pipe: State-of-the-Art Literature Review. J. Perform. Constr. Facil. 2014, 28, 618-628. [CrossRef]

2. Roller, J.J. PCCP Risk Management-State of the Art and Strategy; American Water Works Association: Denver, CO, USA, 2013.

3. Du, X.Y. Study on key techniques for design of PCCP for long-distance diversion project. Water Resour. Hydropower Eng. 2015, 46, 37-49.

4. Zhang, C. Analysis on the Stress of Prestressed Concrete Cylinder Pipe during Wire Winded; Institute of Water Conservancy \& Environment Zhengzhou University: Zhengzhou, China, 2015.

5. Ge, S.Q.; Sunil, S. Effect of Mortar Coating's Bond Quality on the Structural Integrity of Prestressed Concrete Cylinder Pipe with Broken Wires. J. Mater. Sci. Res. 2015, 4, 59-75. [CrossRef]

6. Ball, R.T.; Moore, W.G.; Smith, D.L.; Stubblefield, N.D.; Wahlquist, R.W. Prestressed Concrete Cylinder Pipe Rehabilitation Repair and Replacement: Large Diameter Success Stories. Fla. Water Resour. J. 2012, 4-10.

7. Rahman, S.; Smith, G.; Mielke, R.; Keil, B. Rehabilitation of Large Diameter PCCP: Relining and Sliplining with Steel Pipe. In Proceedings of the Pipelines 2012: Innovations in Design, Construction, Operations, and Maintenance -Doing More with Less, Miami Beach, FL, USA, 19-22 August 2012; pp. 494-504.

8. Kenny, M.K.; Rahman, S. San Diego County Water Authority Aqueduct Protection Program since 1992: Evolution in Design and Construction of Steel Cylinder Relining of PCCP. In Proceedings of the Pipelines 2014: From Underground to the Forefront of Innovation and Sustainability, Portland, OR, USA, 3-6 August 2014.

9. Ambroziak, M.; Kelso, P.E.B.; Sinclair, J. Development and Construction of the Nations Largest Water Main Rehab Project. In Proceedings of the Pipelines 2010: Climbing New Peaks to Infrastructure Reliability: Renew, Rehab, and Reinvest, Keystone, CO, USA, 28 August-1 September 2010; pp. 51-60.

10. Zarghamee, M.S.; McReynolds, M. Retrofit of CFRP Installation to Meet Current Design Standard. In Proceedings of the Pipelines 2013: Pipelines and Trenchless Construction and Renewals-A Global Perspective, Forth Worth, TX, USA, 23-26 June 2013; pp. 1258-1267.

11. Zarghamee, M.S. MuratEngindeniz, CFRP Renewal of PCCP-An Overview. In Proceedings of the Pipelines 2014: From Underground to the Forefront of Innovation and Sustainability, Portland, OR, USA, 3-6 August 2014; pp. 932-941.

12. Dou, T.S.; Cheng, B.Q.; Hu, H.; Xia, S.F.; Zhao, L.J. The experimental study on CFRP renewal of PCCP with broken wires. China Concr. Cem. Prod. 2017, 12, 35-40.

13. L-Hacha, R.E.; Elbadry, M. Strengthening Concrete Beams with Externally Prestressed Carbon Fiber Composite Cables: Experimental Investigation. PTI J. 2006, 4, 53-70.

14. Elnakhat, H.; Raymond, R. Repair of PCCP by Post Tensioning. In Proceedings of the Pipelines 2006, Chicago, IL, USA, 30 July-2 August 2006; pp. 1-5.

15. AWWA C304 Standard for Design of Prestressed Concrete Cylinder Pipe; American Water Works Association: Denver, CO, USA, 2015.

16. Ojdrovic, R.; la Bonte, G. Inspection, Failure Risk Analysis, and Repair of Cooling-Water Lines in One Outage. In Proceedings of the Pipelines 2008: Pipeline Asset Management: Maximizing Performance of our Pipeline Infrastructure, Atlanta, GA, USA, 22-27 July 2008; pp. 1-10.

17. Ye, Z. The External Prestressing and Carbon Fiber Reinforced Joint Concrete Continuous Beam Research; Jilin Architecture and Civil Engineering Institute: Changchun, China, 2012. 
18. Ma, Z. Study on the application of CFRP prestressed tendons in precast segmental bridge. J. Transp. Sci. Eng. 2017, 33, 50-55.

19. Feng, X.Z. Comparison of ASTM Concrete Compressive Strength and China's Concrete Strength Grade. Northwest Hydropower 2008, 3, 65-67. 